\title{
Metabolic Studies on Myelin
}

\section{EVIDENCE FOR A PRECURSOR ROLE OF A MYELIN SUBFRACTION}

\author{
By HARISH C. AGRAWAL, JOHN L. TROTTER, ROBERT M. BURTON \\ and RAYMOND F. MITCHELL* \\ Department of Pediatrics and Neurology and Pharmacology, Washington University School of Medicine, the \\ Division of Neurology, St. Louis Children's Hospital, and the Beaumont-May Institute of Neurology, St. Louis, \\ Mo. 63110, U.S.A.
}

(Received 26 November 1973)

\begin{abstract}
Myelin prepared from brain tissue of the developing rat (15 days post partum) can be separated into several subfractions. These are (1) 'myelin-like' and 'purified myelin', by the technique of Davison and co-workers (Agrawal et al., 1970b) and (2) 'membrane fraction,' 'light myelin' and 'heavy myelin' by the discontinuous-sucrose-gradient procedure described in the present paper. 'Myelin-like' and 'membrane-fraction' subfractions appear to be similar in chemical properties, but different in detailed morphology by electron microscopy. Both fractions are related to myelin, on the basis of demonstrable myelin basic protein by polyacrylamide-gel electrophoresis in sodium dodecyl sulphate and the presence of a myelin-marker enzyme, $2^{\prime}: 3^{\prime}$-cyclic nucleotide $3^{\prime}$-phosphohydrolase. These two fractions have a low lipid content (17\% for 'myelin-like' and $40 \%$ for 'membrane-fraction' subfractions) compared with myelin (67-72\%). No cerebroside was detected in these two fractions, whereas cerebrosides are a major component of myelin itself. The administration of $\left[2,3-{ }^{3} \mathrm{H}\right]$ tryptophan to young rats results in more rapid incorporation into proteins of the 'myelin-like' and 'membrane-fraction' subfractions when compared with incorporation into myelin. Data are presented which are consistent with a precursor-product relationship for conversion of 'myelin-like' and 'membrane-fraction' subfractions into myelin.
\end{abstract}

Horrocks et al. (1966) demonstrated that myelin isolated from developing brain has a different lipid composition from that of mature myelin. This 'young' membrane is enriched in phospholipid and impoverished in cerebroside, hence the molar ratio of phospholipid cholesterol and cerebroside is significantly different from that of mature myelin (Horrocks, 1968). This finding has been confirmed by a number of investigators in myelin isolated from developing brain of a number of species (Cuzner \& Davison, 1968; Eng \& Noble, 1968; Dalal \& Einstein, 1969; Norton, 1971; Norton \& Poduslo, 1973). The myelin prepared from developing brain was defined as 'early myelin' to distinguish it from mature myelin. Davison and co-workers (Banik \& Davison, 1969; Agrawal et al., 1970b) isolated a membrane fraction, called 'myelin-like' material, from 15-day-old rat brain, the chemical composition and morphological characteristics of which were quite different from both early and mature myelin. The myelin-like material contained predominantly single vesicles, much lower concentration and/or absence of cerebroside, and was enriched in high-molecular-weight

* Present address: Australian Atomic Energy Commission, Lucas Heights, N.S.W. 2031, Australia. protein components. The distinguishing feature of this membrane fraction is the high activity of the enzyme 2':3'-cyclic nucleotide 3'-phosphohydrolase compared with other membranes (e.g. microsomal fractions, mitochondria and synaptosomes, and synaptic plasma membranes) in which the activity of this enzyme is very low. Since this enzyme is principally, if not exclusively, localized in the myelin sheath (Kurihara \& Tsukada, 1967; H. C. Agrawal, unpublished work), its high activity in myelin-like material induced Davison and co-workers (Agrawal et al., 1970b) to postulate that 'myelin-like material is a stage in the formation of compact myelin from glial plasma membrane.'

Recently our laboratory has prepared myelin-like material and used a number of criteria for identifying a possible relationship between this membrane fraction and myelin (Agrawal et al., 1973).

Other workers (Morell et al., 1972; Waehneldt \& Mandel, 1972; Benjamins et al., 1973; Poduslo \& Norton, 1973) have also isolated a membrane fraction, similar to myelin-like material in morphological characteristics and protein profile, by either the fractionation procedure developed by $W$. T. Norton \& A. N. Davison (unpublished work) or a 
modification thereof. We have undertaken a systematic study of the 'myelin-like' fraction (ML) isolated by the technique of Davison and co-workers (Agrawal et al., 1970b, 1973) and a 'membrane fraction' (MF) prepared by a procedure evolved in our laboratory (present study). Our method of isolating this membrane fraction also yields two additional components of myelin which we have arbitrarily defined as light and heavy myelin owing to their flotation properties on a discontinuous sucrose gradient. In the present paper we will present evidence, obtained by radioactive-isotope studies, that the proteins of the membrane fraction are more rapidly labelled than either light or heavy myelin in 15-17-day-old rat brain. A similar pattern is seen for myelin-like material and purified myelin. The kinetics of these radioisotopic studies are consistent with the required precursor-product relationship between myelin-like material and myelin and further substantiate the original postulate of Davison and co-workers (Agrawal et al., 1970b) that myelin-like material may be a precursor of myelin. Our results from enzymic studies, protein profile on polyacrylamide-gel electrophoresis and lipid analysis also support this concept.

\section{Experimental}

\section{Chemicals}

All reagents used were analytical grade unless otherwise specified. 2':3'-Cyclic nucleotide cyclohexylguanidinium salt was obtained from Calbiochem, Elk Grove, Ill., U.S.A. 2'-AMP, acetylthiocholine chloride and dithiobis(nitrobenzoic acid) were purchased from Sigma Chemical Co., St. Louis, Mo., U.S.A. Electrophoresis-grade acrylamide was obtained from Eastman, Rochester, N.Y., U.S.A., and methylenebisacrylamide, $N N N^{\prime} N^{\prime}$-tetramethylethylenediamine, ammonium persulphate and Coomassie Brilliant Blue were purchased from Bio-Rad, Richmond, Calif., U.S.A. Sequential-grade sodium dodecyl sulphate was obtained from Pierce Chemical Co., Rockford, IIl., U.S.A. DL-[2,3- $\left.{ }^{3} \mathrm{H}\right]-$ Tryptophan (164 mCi/mmol), Aquasol and Omnifluor were products of New England Nuclear, Boston, Mass., U.S.A. NCS tissue solubilizer was purchased from Amersham/Searle, Arlington Heights, Ill., U.S.A. Electron-microscopic-grade glutaraldehyde was obtained from Taab Laboratories, Reading, Berks., U.K.

\section{Animals}

Sprague-Dawley albino rats were purchased from Zivic Miller Laboratory, Pittsburgh, Pa., U.S.A. The litters were decreased to eight pups at birth. The average body and brain weights of the animals at 1.5 days of age were $32 \pm 3.79$ (S.D.) and $1.25 \pm 0.07$ (s.D.) respectively.

\section{Isolation of subcellular fractions}

(a) Myelin-like fraction ( $M L)$. Eight rat brains (15 days of age) were used for each fractionation. These fractions were prepared essentially by the technique of Agrawal et al. (1970b) with modifications as described by Agrawal et al. (1973).

(b) Light myelin, heavy myelin and membrane fraction $(M F)$. The method of isolating the membrane fraction and other myelin subfractions is described schematically in Fig. 1. Briefly, the brains (eight brains from 15-day-old rats) were homogenized by hand in an all-glass Dounce homogenizer in $0.88 \mathrm{M}$ sucrose $(5 \%, \mathrm{w} / \mathrm{v})$ as described previously (Agrawal et al., 1973). Sucrose $(22 \mathrm{ml}$ of $0.32 \mathrm{M})$ was layered over $16 \mathrm{ml}$ of the homogenate. This gradient was centrifuged for $1 \mathrm{~h}$ at $75000 \mathrm{~g}$ in a SW-27 rotor in a Beckman-Spinco ultracentrifuge model L2-65B. All operations were carried out at $0-4^{\circ} \mathrm{C}$. The myelin floating at the interface was removed with a Pasteur pipette into a Dounce glass homogenizer. It was homogenized by hand with a loose pestle with three up-and-down strokes and osmotically shocked with 9 vol. of water and left at $0-4^{\circ} \mathrm{C}$ for $20 \mathrm{~min}$. It was centrifuged at $75000 \mathrm{~g}$ for $15 \mathrm{~min}$ (Norton, 1971). The pellet was homogenized in ice-cold water and centrifuged at $12500 \mathrm{~g}$ for $10 \mathrm{~min}$ as described by Norton (1971). This step was repeated. The osmotically shocked myelin was resuspended in $0.32 \mathrm{M}$ sucrose by hand homogenization in a Dounce glass homogenizer. The volume was increased to $30 \mathrm{ml}$ with $0.32 \mathrm{M}$-sucrose and six portions of $5 \mathrm{ml}$ were carefully layered over six discontinuous sucrose gradients. The discontinuous gradients were prepared in cellulose nitrate tubes $(40 \mathrm{ml})$ by carefully layering $6 \mathrm{ml}$ of $0.85 \mathrm{M}$-sucrose over $6 \mathrm{ml}$ of $0.88 \mathrm{M}$-sucrose followed by 9 and $12 \mathrm{ml}$ of $0.75 \mathrm{M}$ - and $0.55 \mathrm{M}$-sucrose respectively. These gradients were prepared and kept at $0-4^{\circ} \mathrm{C}$ for at least $3 \mathrm{~h}$ before the layering of the myelin suspension. This set of gradients was centrifuged in a SW-27 rotor for $1 \mathrm{~h}$ at $75000 \mathrm{~g}$. The resulting three bands, i.e. light myelin, heavy myelin, membrane fraction, and a pellet were collected in a Dounce glass homogenizer, homogenized and the volume increased to $100 \mathrm{ml}$ with water. These fractions were centrifuged in a Beckman-Spinco 30 rotor at $100000 \mathrm{~g}(30000 \mathrm{rev} / \mathrm{min})$ for $30 \mathrm{~min}$. These fractions were resuspended in water by hand homogenization and centrifuged at $100000 \mathrm{~g}$ for $30 \mathrm{~min}$ as described above. For lipid analysis, these fractions were washed two times with $100 \mathrm{ml}$ of water and three times with $30 \mathrm{ml}$ of water as described above to remove sucrose. The increased number of washings did not change the biochemical and morphological 

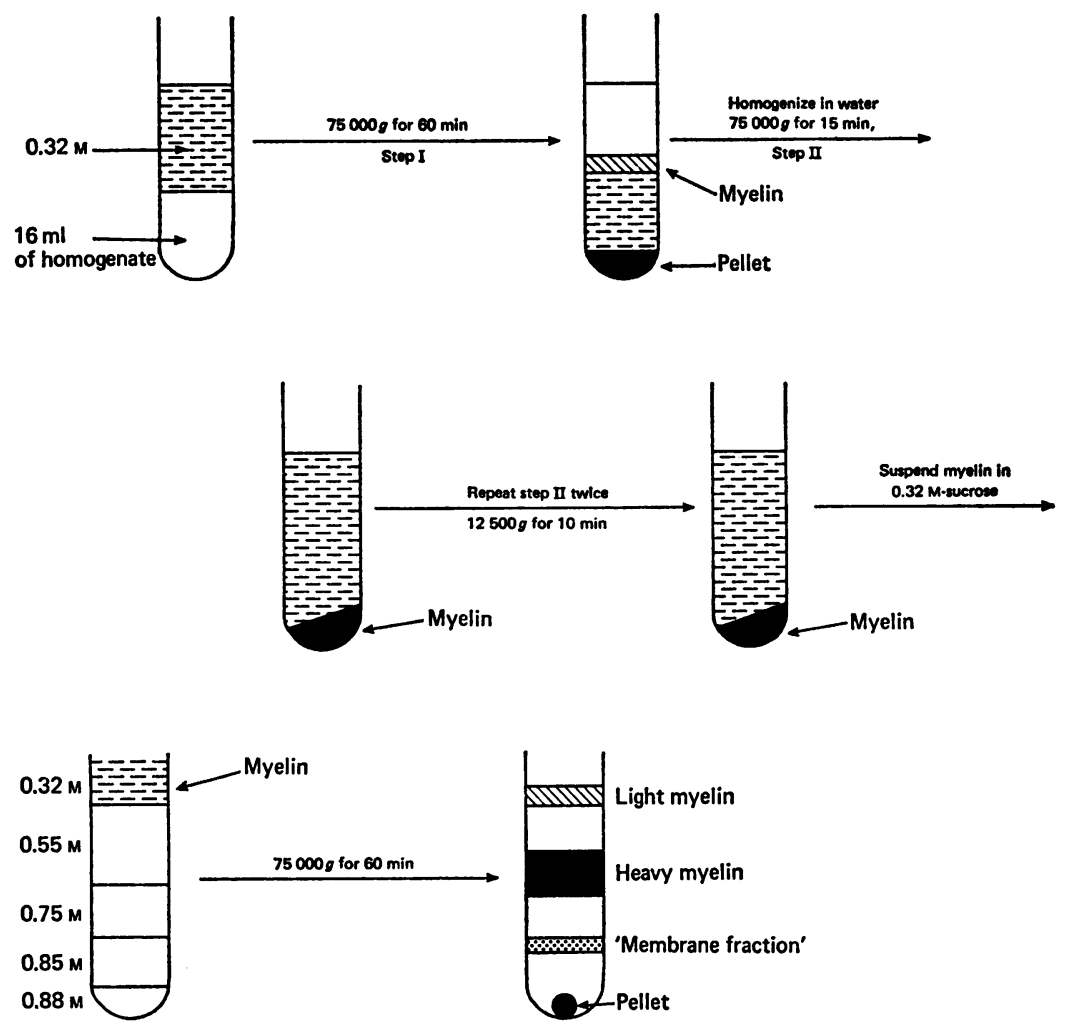

Fig. 1. Isolation of myelin subfractions from myelin of developing rat brain

Additional details are provided in the text.

characteristics of these fractions compared with those washed with water twice.

(c) Other subcellular fractions. These were prepared by the procedure of De Robertis et al. (1962) with modifications (Agrawal et al., 1973).

\section{Storage of subcellular particles}

All fractions were diluted with water and centrifuged for $30 \mathrm{~min}$ at $100000 \mathrm{~g}$. The pellets derived were resuspended in water and stored at $-75^{\circ} \mathrm{C}$ until needed for enzymic or other chemical analysis.

\section{Electron microscopy}

Pellets were first fixed in $0.1 \mathrm{M}$-cacodylate buffer containing $3 \%(\mathrm{v} / \mathrm{v})$ glutaraldehyde $(\mathrm{pH} 7.2)$ at $0-4^{\circ} \mathrm{C}$. The pellets were washed with $0.1 \mathrm{M}$-cacodylate buffer to remove residual glutaraldehyde and then fixed in $1 \%(\mathrm{w} / \mathrm{v})$ osmium tetroxide in $0.1 \mathrm{M}$-cacodylate buffer $(\mathrm{pH} 7.2)$. After $5 \mathrm{~min}$ at $0-4^{\circ} \mathrm{C}$, the tubes containing the pellets were placed at room temperature and fixation was allowed to continue for 30 $60 \mathrm{~min}$. The excess of osmium tetroxide was removed by washing the pellets thoroughly with water. The pellets were next stained in a $2 \%(w / v)$ aqueous solution of uranyl acetate for $1 \mathrm{~h}$ at room temperature. The excess of uranyl acetate was removed by washing with water. The blocks were dehydrated in increasing concentrations of ethanol $(10-100 \%$, $\mathrm{v} / \mathrm{v}$ ) and propylene oxide and embedded in Araldite. Ultrathin sections were cut and examined with a Phillips electron microscope. When sufficient material was available, a number of sections were scanned to determine the extent of contamination of the membrane and myelin subfractions with other subcellular organelles.

\section{Measurement of enzyme activity}

The activity of $2^{\prime}: 3^{\prime}$-cyclic nucleotide $3^{\prime}$-phosphohydrolase was determined by the method of Kurihara 
\& Tsukada (1967) under the conditions described by Banik \& Davison (1969) except that the chromatograms were developed in the solvent system overnight $(16 \mathrm{~h})$ for the complete separation of nucleotides. All samples were suspended in an equal volume of $1 \%(w / v)$ Triton X-100 and kept in an ice chest at $0^{\circ} \mathrm{C}$ for $30 \mathrm{~min}$ (with vigorous mixing every $5-10 \mathrm{~min}$ ) before the measurement of enzyme activity. Since only $1-1.5 \mu \mathrm{g}$ of myelin proteins was required to attain $40-50 \%$ hydrolysis of the substrate, $2^{\prime}: 3^{\prime}$-cyclic nucleotide, we determined the total proteins in all samples diluted with $0.2 \mathrm{M}-\mathrm{Na}_{2} \mathrm{HPO}_{4}-0.1 \mathrm{M}$-citric acid buffer ( $\mathrm{pH}$ 6.2). Two other observations were made before measuring the enzyme activity in different fractions.

(a) The enzyme was not activated simply by freezing and thawing four times from $-140^{\circ} \mathrm{C}$ to $0^{\circ} \mathrm{C}$ in the absence of Triton X-100; therefore the detergent was used with all fractions assayed.

(b) Since it took us about 12-15h to prepare both the myelin-like and membrane fractions it became necessary to test the stability of the $2^{\prime}: 3^{\prime}$-cyclic nucleotide $3^{\prime}$-phosphohydrolase during this timeinterval. Therefore 15-day-old rats were killed with an overdose of sodium pentobarbital $(60 \mathrm{mg})$ and some animals were left at room temperature $\left(25^{\circ} \mathrm{C}\right)$ and some in the cold-room $\left(0-4^{\circ} \mathrm{C}\right)$ for $12 \mathrm{~h}$. Then myelin was isolated by the procedure developed in this laboratory (Agrawal et al., 1972) and washed as described by Norton (1971). There was no loss of the enzyme activity of myelin isolated from the brains of rats kept at $25^{\circ} \mathrm{C}$ or $0-4^{\circ} \mathrm{C}$ compared with controls, suggesting that this enzyme is not degraded by brain proteinases or other proteolytic enzymes under these conditions (J. L. Trotter, M. A. Fishman \& H. C. Agrawal, unpublished work).

Acetylcholinesterase (EC 3.1.1.7) activity was determined by the method described by Ellman et al. (1961). $\beta$-Hydroxybutyrate dehydrogenase (EC 1.1.1.30) activity was determined by the method of Williamson et al. (1971). Protein concentration was determined by the method of Lowry et al. (1951) as modified by Hess \& Lewin (1965). Crystalline bovine serum albumin was used as a standard.

\section{Lipid analysis}

The lipid composition of the membrane fraction and other myelin subfractions was determined after their extraction with ether-ethanol $(3: 2, \mathrm{v} / \mathrm{v})$ twice, once with diethyl ether, and finally with chloroformmethanol $(2: 1, v / v)$. The supernatants were combined and dried under $\mathrm{N}_{2}$. The lipids were dissolved in chloroform-methanol $(2: 1, \mathrm{v} / \mathrm{v})$ and partitioned with water (Folch et al., 1957). The washed lipids were dissolved in chloroform-methanol $(2: 1, \mathrm{v} / \mathrm{v})$ and examined by t.l.c. (Redi-coats from Supelco Inc., Bellefonte, Pa., U.S.A.) in chloroform-methanol- water $(65: 25: 4$, by vol.) as the developing solvent. Cholesterol was measured directly (Courchaine et al., 1959; Zlatkis et al., 1963). Total phospholipids and individual phospholipids (after chromatography on Whatman SG-81) were determined by the procedure of Bartlett (1959). Cerebrosides were determined by the procedure of Siakotos et al. (1971) after t.l.c.

\section{Polyacrylamide-gel electrophoresis}

Polyacrylamide-gel electrophoresis in sodium dodecyl sulphate was carried out as described previously (Agrawal et al., 1972). Electrophoresis was done in glass tubes with internal diameter $6 \mathrm{~mm}$ and a length $150 \mathrm{~mm}$. The tubes were filled to a height of $115 \mathrm{~mm}$ with $10 \%(\mathrm{w} / \mathrm{v})$ acrylamide solution and overlayered with water to a height of $10 \mathrm{~mm}$ as described previously (Agrawal et al., 1972). After polymerization was complete (usually $15-20 \mathrm{~min}$ ) the tubes were left at room temperature at least for $60 \mathrm{~min}$ before use.

The subcellular fractions were partially delipidated by suspension in ether-ethanol $(3: 2, v / v)$ and centrifugation. This step was repeated four times. The samples were then suspended in anhydrous diethyl ether, centrifuged, and dried under $\mathrm{N}_{2}$. The residue was dissolved in sample buffer containing $5 \mathrm{~mm}$-sodium phosphate buffer, $8 \%(\mathrm{w} / \mathrm{v})$ sucrose and $1 \%(\mathrm{w} / \mathrm{v})$ sodium dodecyl sulphate, $\mathrm{pH}$ 7.2. The protein concentration of sodium dodecyl sulphatesolubilized protein was determined by the technique of Lowry et al. (1951). Dithiothreitol $(1.5 \%$, w/v) and an aqueous solution of Bromophenol Blue $(0.05 \%, w / v)$ were added to a sample of each protein solution before use. This mixture was heated to $100^{\circ} \mathrm{C}$ for $2 \mathrm{~min}$ and then allowed to cool for at least $30 \mathrm{~min}$ before use. This solution was layered on the gels and overlayered carefully with electrode buffers (Agrawal et al., 1972).

The gel electrophoresis was carried out in an apparatus made by Hoeffer Scientific Co., San Francisco, Calif., U.S.A. The current was $0.5 \mathrm{~mA} / \mathrm{gel}$ for $5 \mathrm{~h}$, then increased to $1.0 \mathrm{~mA} / \mathrm{gel}$ and maintained for $15-18 \mathrm{~h}$. It was then increased to $4 \mathrm{~mA} / \mathrm{gel}$ for $2 \mathrm{~h}$. The gels were stained for $18 \mathrm{~h}$ in $0.25 \%$ Coomassie Brilliant Blue dissolved in $45 \%(\mathrm{v} / \mathrm{v})$ methanol-10\% (v/v) acetic acid. Destaining was carried out by diffusion as described previously (Allison et al., 1974). It was not possible to localize the protein band corresponding to $2^{\prime}: 3^{\prime}$-cyclic nucleotide $3^{\prime}$-phosphohydrolase in the sodium dodecyl sulphate gel system because the enzyme activity was completely inhibited at all concentrations $(0.1-1.0 \%, \mathrm{w} / \mathrm{v})$ of sodium dodecyl sulphate.

\section{Radioactive tracer studies}

Each member of the litter of 15-day-old rats was injected intraperitoneally with $50 \mu \mathrm{Ci}$ of $\left[2,3-{ }^{3} \mathrm{H}\right]-$ 
tryptophan $(164 \mathrm{mCi} / \mathrm{mmol})$ in a total volume of $50 \mu \mathrm{l}$ and killed by decapitation after intervals ranging from $15 \mathrm{~min}$ to $96 \mathrm{~h}$. One litter was used for each time-point, except the $15 \mathrm{~min}$ time-point where two litters were used for each fractionation. Homogenate and other subcellular fractions were prepared as described above.

\section{Preparation of proteins for radioactivity determinations}

Proteins were precipitated with an equal volume of ice-cold $20 \%(\mathrm{w} / \mathrm{v})$ trichloroacetic acid, left for at least $1 \mathrm{~h}$ at $0-4^{\circ} \mathrm{C}$ and then centrifuged. The pellets were resuspended and washed twice in cold $10 \%(\mathrm{w} / \mathrm{v})$ trichloroacetic acid and centrifuged. The supernatants were discarded from all subcellular fractions except the homogenate, which was kept for the measurement of radioactivity in tricarboxylic acidcycle metabolites and in other amino acids. The resultant precipitates were suspended in $4 \mathrm{ml}$ of $5 \%$ (w/v) trichloroacetic acid and heated for $15 \mathrm{~min}$ in a water bath at $90^{\circ} \mathrm{C}$, allowed to cool and centrifuged to remove nucleic acid. This precipitate was resuspended in $5 \%(w / v)$ trichloroacetic acid twice and centrifuged. To remove the lipid material, the residue was successively washed three times in ethanol-ether $(3: 1, \mathrm{v} / \mathrm{v})$ and twice in diethyl ether as described by Agrawal et al. (1970a). The residue was dissolved in $0.5 \mathrm{M}-\mathrm{NaOH}$ and incubated overnight $(18 \mathrm{~h})$ at $37^{\circ} \mathrm{C}$. It was necessary to heat this solution to $60^{\circ} \mathrm{C}$ for $1-2 \mathrm{~h}$ to solubilize myelin proteins completely. Samples of this solution were assayed for protein by the procedure of Lowry et al. (1951). Radioactivity was measured by adding 5 vol. of NCS solubilizer to $0.5 \mathrm{ml}$ of protein solution followed by $10 \mathrm{ml}$ of scintillation fluid $(4 \mathrm{~g}$ of Omnifluor to 1 litre of scintillation-grade toluene) and leaving the samples overnight at $4^{\circ} \mathrm{C}$, then counting for radioactivity with a Packard Tri-Carb scintillation spectrometer model 3375 maintained at $4^{\circ} \mathrm{C}$. The counting efficiency was $38 \%$, as determined by both externalstandard ratio and internal standardization.

\section{Results}

\section{Morphological characteristics of myelin subfractions}

The membrane fraction (MF) predominantly contained single-walled vesicles (Plate 1). An interesting difference between this and the myelin-like fraction was that the vesicle wall in the membrane fraction appeared not to be a unit membrane as in the myelin-like fraction, but to have a central dense line with a thinner dense line surrounding it on either side (Agrawal et al., 1973). The implication would be that the vesicle wall of the membrane fraction was composed of two fused unit membranes, whereas the myelin-like vesicles had only a single unit membrane. Since the membrane fraction is present in very small quantity, extensive electronmicroscopic scanning could not be done. Therefore the possibility cannot be ruled out that it is completely devoid of myelin fragments; however, the presence of myelin cannot be extensive in view of metabolic and chemical data to be presented below.

The light myelin (LM) fraction consisted mainly of small vesicles, many of which contained electrondense material (Plate 1). The heavy myelin (HM) fraction consisted of many myelin figures (Plate 1), which were in general larger than the small vesicles of light myelin, but heavy myelin in addition contained more small vesicles than are usually found in myelin (Agrawal et al., 1973).

The pellet $(P)$ contained a mixture of mitochondria, nerve-ending particles, axon fragments and very little myelin. The morphological characteristics of this fraction are in contrast with the findings of Benjamins et al. (1973), who reported the presence of predominantly single vesicles in their $\mathrm{D}$ or pellet fraction. The reason for this discrepancy is not clear; however, it may lie in subtle differences in the methods used for the isolation of myelin subfractions.

\section{Lipid composition of the myelin subfractions}

Table 1 presents the results of lipid extraction and analysis of a single preparation of each myelin subfraction. Myelin contains more total lipid than do the myelin-like and membrane fractions. Of special interest is the lack of detectable cerebroside in either myelin-like or membrane fractions. Davison and co-workers (Banik \& Davison, 1969; Agrawal et al., $1970 b$ ) reported that the myelin-like fraction contained very little cerebroside. The myelin-like fraction appears to contain more phospholipid relative to cholesterol than do any of the myelin fractions. However, such a marked increase in phospholipid/ cholesterol ratio is not observed with the membrane fraction, MF. It is noteworthy that although the subfractions were washed with large volumes of water five times, the resultant aqueous phase from the partitioning of the lipids by the Folch procedure contained significant amounts of sucrose, sufficient to interfere with direct carbazole- $\mathrm{H}_{2} \mathrm{SO}_{4}$ measurements of cerebrosides and colorimetric determinations of gangliosides.

\section{Enzyme activity}

Three marker enzymes, i.e. $2^{\prime}: 3^{\prime}$-cyclic nucleotide 3'-phosphohydrolase, acetylcholinesterase (EC 3.1.1.7) and $\beta$-hydroxybutyrate dehydrogenase (EC 1.1.1.30) were monitored to ascertain the purity of membrane fractions and subfractions of myelin.

When myelin was subfractionated on a multiple disconti uous gradient (Fig. 1) there was a gradient 
Table 1. Lipid composition of myelin subfractions prepared from 15-day-old rat brain

Details are given in the text. N.D., None detectable.

\begin{tabular}{|c|c|c|c|c|c|c|}
\hline Fraction & $\begin{array}{c}\text { Dry weight } \\
\text { of sample } \\
\text { (mg) }\end{array}$ & $\begin{array}{l}\text { Lipid-free } \\
\text { dry weight } \\
\text { (mg) }\end{array}$ & $\begin{array}{c}\text { Washed } \\
\text { lipids } \\
\text { (mg) }\end{array}$ & $\begin{array}{c}\text { Cholesterol } \\
(\mu \mathrm{mol})\end{array}$ & $\begin{array}{l}\text { Phospholipids } \\
(\mu \text { mol })\end{array}$ & $\begin{array}{c}\text { Cerebrosides } \\
(\mu \mathrm{mol})\end{array}$ \\
\hline $\begin{array}{l}\text { Membrane Fraction (MF) } \\
\text { Heavy myelin } \\
\text { Light myelin } \\
\text { 'Myelin-like' } \\
\text { Myelin* } \\
\text { Microsomal fractions }\end{array}$ & $\begin{array}{r}1.0 \\
12.9 \\
4.3 \\
11.9 \\
16.5 \\
55.7\end{array}$ & $\begin{array}{r}0.6 \\
2.0 \\
0.8 \\
6.7 \\
2.6 \\
42.2\end{array}$ & $\begin{array}{l}0.4(0.2 \%) \dagger \\
8.7(0.4 \%) \dagger \\
3.1(0.2 \%) \dagger \\
2.0(0.7 \%) \dagger \\
8.2(1.0 \%) \dagger \\
8.4(1.2 \%) \dagger\end{array}$ & $\begin{array}{l}0.33(1.00) \ddagger \\
5.93(1.00) \ddagger \\
2.07(1.00) \ddagger \\
1.01(1.00) \ddagger \\
5.44(1.00) \ddagger \\
6.31(1.00) \ddagger\end{array}$ & $\begin{array}{l}0.43(1.30) \ddagger \\
6.86(1.16) \ddagger \\
2.16(1.04) \ddagger \\
1.76(1.74) \ddagger \\
7.34(1.35) \ddagger \\
9.69(1.54) \ddagger\end{array}$ & $\begin{array}{l}\text { N.D. }(-) \ddagger \\
3.62(0.61) \ddagger \\
1.37(0.66) \ddagger \\
\text { N.D. }(-) \ddagger \\
1.63(0.3) \S \\
0.25(0.04) \ddagger\end{array}$ \\
\hline
\end{tabular}

Table 2. Distribution of 2':3'-cyclic nucleotide 3'phosphohydrolase and acetylcholinesterase activity in membrane and other myelin subfractions of 15-day-old rat brain

The data represent the means \pm S.E.M. of three to six different preparations of membrane and myelin subfractions. Eight animals were used for each fractionation.

\section{Fractions

$$
\begin{gathered}
2^{\prime}: 3^{\prime} \text {-Cyclic nucleotide } \\
3^{\prime} \text {-phosphohydrolase } \\
\text { ( } \mu \text { mol of } 2^{\prime}-\text { AMP formed } \\
\text { h per mg of protein) }
\end{gathered}
$$ ( $\mu$ mol of 2'-AMP formed/}

Homogenate

Light myelin

Heavy myelin

Membrane

Pellet
(A)

$$
\begin{gathered}
107 \pm 6.8(5) \\
1384 \pm 147(3) \\
1300 \pm 106(6) \\
1058 \pm 28(4) \\
546 \pm 72(3)
\end{gathered}
$$

\section{Acetylcholinesterase \\ ( $\mu \mathrm{mol}$ of acetylthiocholine hydrolysed/h per $\mathrm{mg}$ of protein)}

$$
\begin{aligned}
& 4.74 \pm 0.25(3) \\
& 0.17 \pm 0.02(3) \\
& 1.33 \pm 0.05(4) \\
& 4.91 \pm 0.51(5) \\
& 3.68 \pm 9.36(4)
\end{aligned}
$$

Ratio A/B

23
8141
977
216
148

of activities of both enzymes. The highest activity of $2^{\prime}: 3^{\prime}$-cyclic nucleotide $3^{\prime}$-phosphohydrolase was in light myelin and the lowest was in the membrane fraction (Table 2). In contrast, the highest activity of acetylcholinesterase was found in the membrane fraction (MF) and was barely detectable in light myelin (Table 2). This fact becomes readily apparent when the ratios of the two enzyme activities are examined (Table 2). Appreciable activity of both enzymes was detected in the pellet, which is a mixture of a variety of subcellular membranes (Plate 1) including myelin (Table 2). No $\beta$-hydroxybutyrate dehydrogenase activity was present either in light or heavy myelin. The activity of this enzyme, if present, in the membrane fraction was so low that it was below the sensitivity of the method.

\section{Protein profile by polyacrylamide gel electrophoresis in sodium dodecyl sulphate}

The myelin subfractions prepared by our procedure were subjected to sodium dodecyl sulphate-polyacrylamide-gel electrophoresis. The protein profile of the membrane fraction (MF) was strikingly similar to that of myelin-like material (Agrawal et al., 1973). Again, there was a predominance of high-molecularweight protein compared with the presence of low, but distinct, amounts of basic proteins (Plate 2). The protein profiles of both light and heavy myelin were qualitatively similar to that of myelin itself (Agrawal et al., 1973).

\section{Metabolic studies}

To study both the temporal and relative labelling of proteins of myelin-like and other subcellular fractions, 15-day-old animals were injected with $50 \mu \mathrm{Ci}$ of $\left[2,3-{ }^{3} \mathrm{H}\right]$ tryptophan/animal (see the Experimental section for details) and killed at time-intervals from $15 \mathrm{~min}$ to $96 \mathrm{~h}$. As might be expected, the specific radioactivity of the microsomal fraction was highest relative to other subcellular fractions $15 \mathrm{~min}$ after the administration of the labelled precursor. The specific radioactivities of myelin-like fractions at $15 \mathrm{~min}$ and $60 \mathrm{~min}$ were 2284 and 6288 c.p.m./mg of protein respectively. This was approximately twice that of purified myelin (Table 3 ). The specific radioactivities of myelin-like and purified myelin were essentially 
(a)

(b)

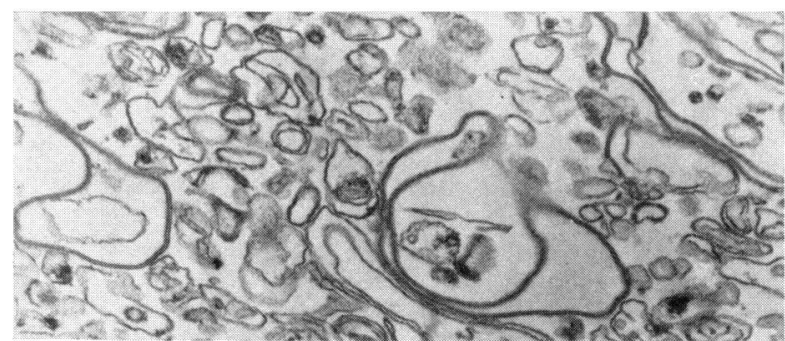

(c)

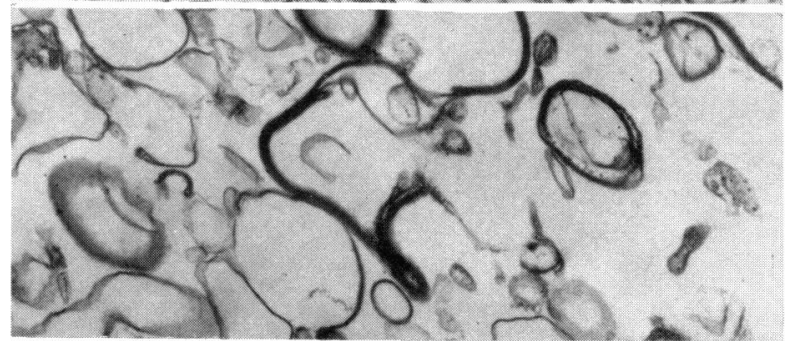

(d)
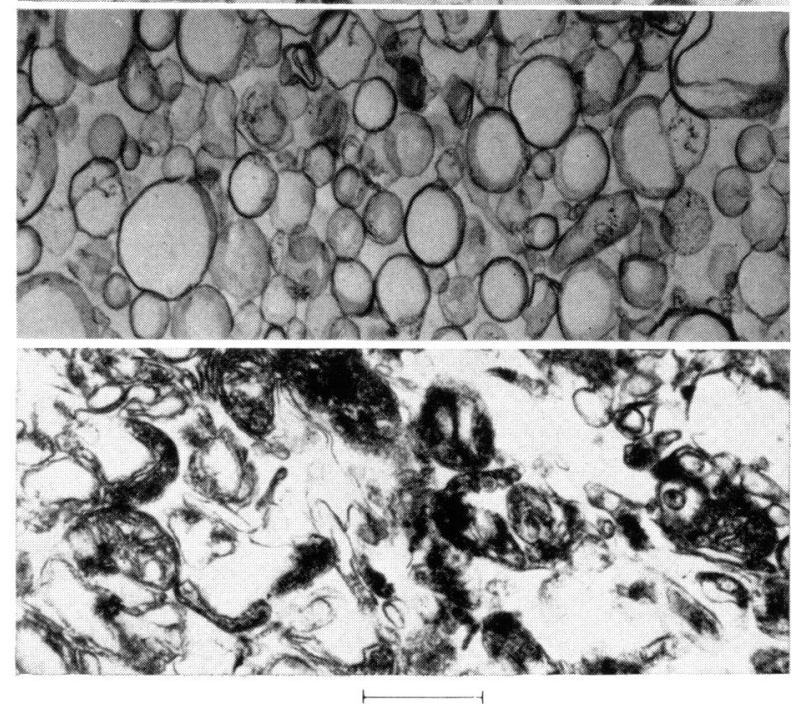

EXPLANATION OF PLATE I

Electron micrographs of myelin subfractions prepared from 15-day-old rat brain as described in the text and Fig. 1 (a) Light myelin; (b) heavy myelin; (c) membrane fraction; (d) pellet. For details see the text. Magnification $\times 34200$. 


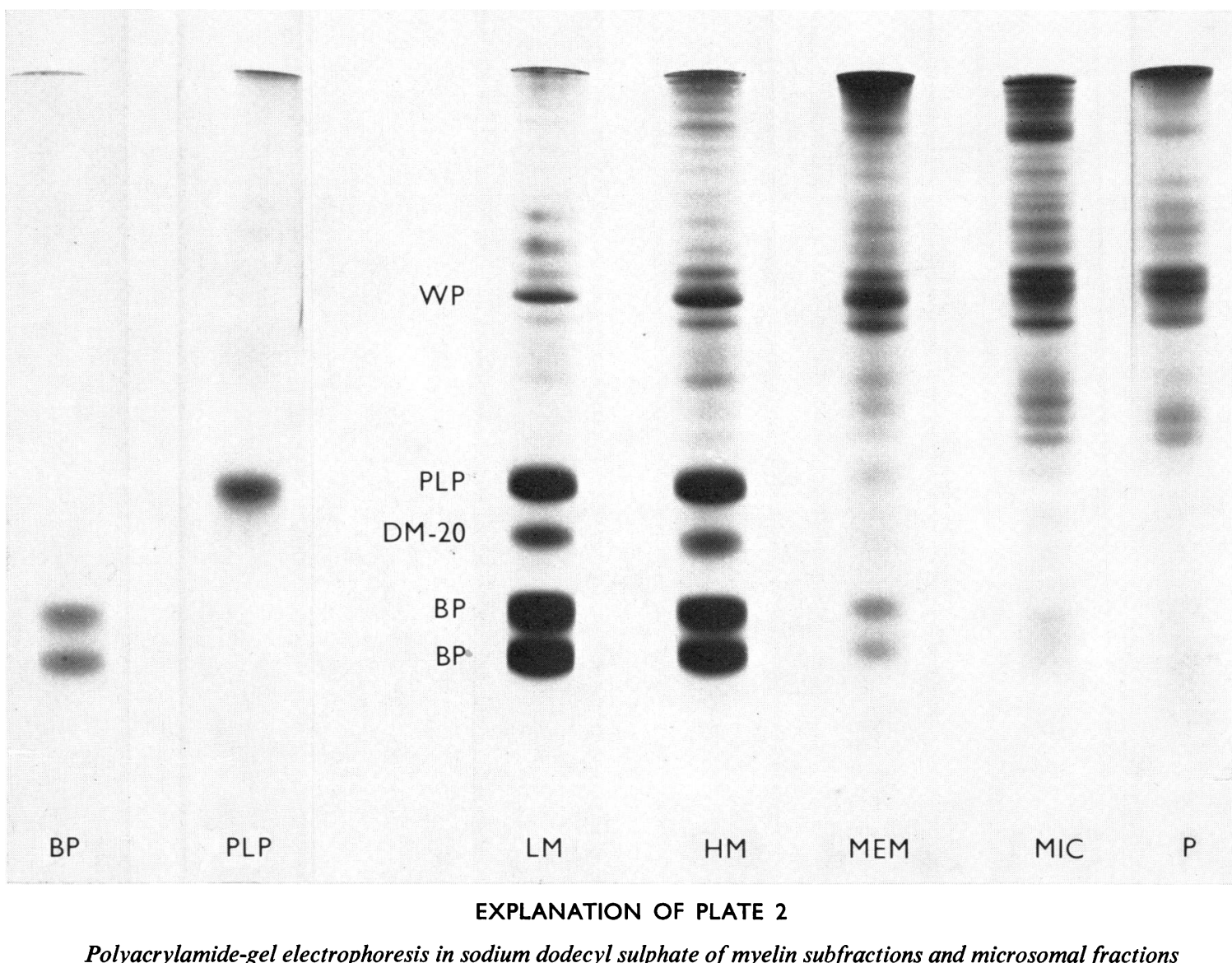

Details of the methods are provided in the text. BP (myelin basic proteins) and PLP (myelin proteolipid lipoprotein) were prepared by preparative gel electrophoresis in sodium dodecyl sulphate. LM, light myelin; HM, heavy myelin; MEM, membrane fraction; MIC, microsomal fraction; P, pellet. Protein $(40 \mu \mathrm{g})$ was applied to all gels except BP and PLP standards. WP, Wolfgram protein; PLP, proteolipid lipoprotein; DM-20 (Agrawal et al., 1972); BP, myelin basic protein. 
Table 3. Incorporation of $\left[2,3-{ }^{3} \mathrm{H}\right]$ tryptophan into proteins of myelin and myelin-like fraction

Eight animals were used for each time-point. The $15 \mathrm{~min}$ time-point was done twice. Results are means \pm S.D. Rats were injected at 15 days of age and killed at subsequent time-intervals as indicated. For details see the Experimental section.

Specific radioactivity (c.p.m./mg of protein)

\begin{tabular}{|c|c|c|c|c|c|c|}
\hline Subcellular fractions & Time ... & $15 \mathrm{~min}$ & $60 \mathrm{~min}$ & $12 \mathrm{~h}$ & $24 \mathrm{~h}$ & $36 \mathrm{~h}$ \\
\hline $\begin{array}{l}\text { Myelin-like } \\
\text { 'urified myelin }\end{array}$ & & $\begin{array}{l}2284 \pm 224 \\
1026 \pm 60\end{array}$ & $\begin{array}{l}6288 \\
3394\end{array}$ & $\begin{array}{l}11875 \\
10483\end{array}$ & $\begin{array}{l}16264 \\
17247\end{array}$ & $\begin{array}{l}10312 \\
9739\end{array}$ \\
\hline
\end{tabular}

Table 4. Incorporation of $\left[2,3-{ }^{3} \mathrm{H}\right]$ tryptophan into proteins of membrane and myelin subfractions derived from myelin isolated from 15-19-day-old rat brain

The membrane and myelin subfractions were prepared by the technique developed in this laboratory (see Fig. 1 and the Experimental section). Eight animals were used for each time-point. The values at $15 \mathrm{~min}$ are averages of two separate experiments on eight rats, i.e. means \pm S.D. of two values. Rats were injected at 15 days of age and killed at subsequent time-intervals as indicated. For details see the Experimental section.

Specific radioactivity (c.p.m./mg of protein)

\begin{tabular}{|c|c|c|c|c|c|c|c|c|}
\hline Subcellular fractions & Time & $\ldots$ & $15 \mathrm{~min}$ & $60 \mathrm{~min}$ & $12 \mathrm{~h}$ & $24 h$ & $48 h$ & $96 \mathrm{~h}$ \\
\hline Homogenate & & & $2346 \pm 215$ & 5442 & 8810 & 8039 & 8558 & 6893 \\
\hline Light myelin & & & $691 \pm 146$ & 3259 & 8346 & 9632 & 8175 & 6375 \\
\hline Heavy myelin & & & $744 \pm 155$ & 3081 & 7660 & 9737 & 10274 & 79 \\
\hline Membrane & & & $1155 \pm 219$ & 5508 & 10090 & 8742 & 9970 & 7792 \\
\hline Pellet & & & $821 \pm 208$ & 4171 & 7552 & 7439 & 7017 & 7035 \\
\hline
\end{tabular}

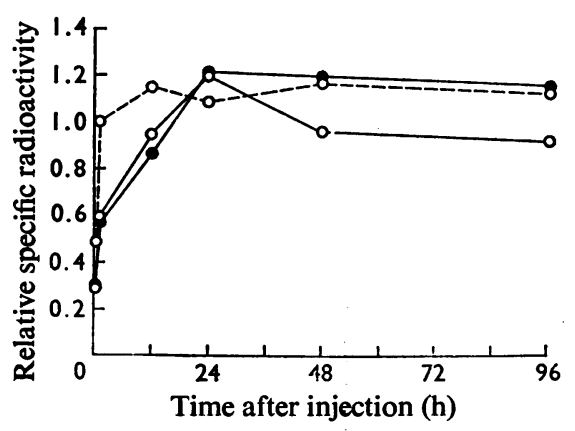

Fig. 2. Relative specific radioactivity of membrane and other subfractions of myelin

The relative specific radioactivity of each fraction was determined by dividing the specific radioactivity (c.p.m./ $\mathrm{mg}$ of protein) by the specific radioactivity of the homogenate to normalize the data. $O$, Heavy myelin; $\mathrm{O}-\mathrm{O}$, light myelin, $\mathrm{O}----\mathrm{O}$, membrane fraction.

the same after $12 \mathrm{~h}$. The decrease in specific radioactivity of these two fractions at $36 \mathrm{~h}$ might indicate dilution of these two fractions with newly formed non-radioactive myelin during this active period of myelination (Davison \& Dobbing, 1966; Agrawal \& Davison, 1973).

Similar radioactive-isotopic studies were carried out on the membrane fraction and other myelin subfractions (prepared as described in Fig. 1) under identical experimental conditions. Similar to our findings in the enzyme study (Table 2), there was a gradient of specific radioactivity between light myelin, heavy myelin and the membrane fraction from $15 \mathrm{~min}$ until $12 \mathrm{~h}$. The specific radioactivity of the membrane fraction was approx. $67 \%$ greater than that of light myelin at the $15 \mathrm{~min}$ and $41 \%$ at the $60 \mathrm{~min}$ time-points (Table 4). After $12 \mathrm{~h}$ the specific-radioactivity difference was only $17 \%$ and at $24 \mathrm{~h}$ both the specific and relative specific radioactivities of both light and heavy myelin were higher than those of the membrane fraction (Table 4; Fig. 2). The specific radioactivities of all fractions decreased after $96 \mathrm{~h}$. The decrease in specific radioactivity of the light myelin was more pronounced relative to heavy myelin and membrane fraction (Table 4). The pellet is composed of a mixture of cellular organelles which shows a slower increase in radioactivity during this time-period than the membrane fraction (Table 4).

\section{Discussion}

The presence of a membrane fraction similar in morphological and biochemical characteristics to myelin-like material, originally described by Davison and co-workers (Banik \& Davison, 1969; Agrawal et al., 1970b), has been confirmed by a number of workers who used different procedures for its isolation. The fact that it floats on a different density 
of sucrose (Banik \& Davison, 1969; Agrawal et al., $1970 b$ ) and Ficoll (W. T. Norton \& A. N. Davison, unpublished work; Morell et al., 1972) than myelin and other myelin subfractions (Poduslo \& Norton, 1973; Benjamins et al., 1973; and this present study, see Fig. 1) would imply that it has a different protein/ lipid ratio, hence higher density. There is evidence to support this contention (Agrawal et al., 1970b); Benjamins et al., 1973; Poduslo \& Norton, 1973; Agrawal et al., 1973). The myelin-like material is enriched in high-molecular-weight proteins, whereas cerebrosides are present only in very small amounts or are absent. These biochemical characteristics of myelin-like fraction are in sharp contrast with the protein and lipid composition of purified myelin (Agrawal et al., 1973) and myelin subfractions (Table 1 and Plate 2). In contrast with the previous study of myelin-like material (Agrawal et al., 1970b), recent studies have demonstrated the presence of myelin basic protein in both myelin-like (Adams \& Osborne, 1973; Morell et al., 1972; Agrawal et al., 1973) and membrane fraction (Benjamins et al., 1973; Poduslo \& Norton, 1973; present study, see Plate 2). Although this is not a definitive proof of a relationship between these fractions and myelin, it is consistent with such a relationship. The only piece of positive evidence linking myelin-like material to myelin subfractions is the strikingly high activity of the enzyme $2^{\prime}: 3^{\prime}$-cyclic nucleotide $3^{\prime}$-phosphohydrolase, an enzyme considered to be primarily, if not exclusively, localized in the myelin membrane (Kurihara \& Tsukada, 1967; H. C. Agrawal, unpublished work).

Pitfalls of subcellular fractionation by densitygradient centrifugation for isolating pure cellular or subcellular organelles are well known; we know that all the subcellular fractions prepared by densitygradient centrifugations are contaminated with myelin. However, the specific activity of the enzyme $2^{\prime}: 3^{\prime}$-cyclic nucleotide $3^{\prime}$-phosphohydrolase is very low in other subcellular fractions, e.g. microsomal fractions $49 \pm 13$ and synaptosomes $55 \pm 8 \mu \mathrm{mol}$ of $2^{\prime}-$ AMP produced/h per $\mathrm{mg}$ of protein when compared with myelin-like material, i.e. 764 \pm 76 (Agrawal et al., 1973) or membrane fraction (Table 2). However, it must be emphasized that the specific activity of this enzyme is very high in the membrane fraction (Table 2) even though this fraction contains many high-molecular-weight proteins quantitatively in excess of those found in myelin or myelin subfractions. Other subcellular fractions also contain large amounts of high-molecular-weight proteins (Plate 2; compare microsomal with membrane fraction), but the specific activity of $2^{\prime}: 3^{\prime}$-cyclic nucleotide $3^{\prime}$-phosphohydrolase is low. It is worth mentioning that this enzyme has been shown to be associated with a minor high-molecular-weight protein of the myelin membrane by polyacrylamide-gel electrophoresis in the absence of sodium dodecyl sulphate (Braun \& Barchi, 1972).

The results of other enzymic analysis, e.g. $\beta$ hydroxybutyrate dehydrogenase, would eliminate the possibility that myelin-like material is derived from or contaminated with mitochondria. The higher activity of acetylcholinesterase would imply that it is derived from either microsomal fractions or synaptosomal complex or contains axonal and neuronal membranes, which are known to be enriched in this enzyme. Therefore synaptosomal plasma membrane was prepared by the technique of Cotman \& Matthews (1971). The specific activity of acetylcholinesterase in the synaptosomal plasma membrane was at least 10 times higher, and that of $2^{\prime}: 3^{\prime}$-cyclic nucleotide 3'-phosphohydrolase approximately four times lower $\left(212 \mu \mathrm{mol}\right.$ of $2^{\prime}$-AMP produced $/ \mathrm{h}$ per $\mathrm{mg}$ of protein) than in the myelin-like subfraction (Agrawal et al., 1973) and the membrane fraction (present study, Table 2). The protein profile in gel electrophoresis in sodium dodecyl sulphate of synaptosomal membrane is far more complex and qualitatively different from the myelin-like material. The presence of myelin basic protein in the membrane fraction was confirmed by two different methods. The pure myelin basic proteins were isolated (Plate 2) and mixed with the membrane fraction; the two protein bands (labelled BP, Plate 2) of the membrane fraction migrated together with the pure myelin basic-protein standard, suggesting that these two protein bands are identical because of their similar mobility and molecular weight. Similar results were obtained on mixing either light or heavy myelin proteins with membrane fraction. Since these two protein bands (Plate 2) in the membrane fraction were heavily labelled by $\left[2,3-{ }^{3} \mathrm{H}\right]$ tryptophan, the possibility that they are only histones can be ruled out. The preponderance of high-molecular-weight proteins (particularly in the region where Wolfgram protein is localized in both light and heavy myelin) in the membrane fraction is consistent with the previous observations (Agrawal et al., 1970b; Morell et al., 1972; Waehneldt \& Mandel, 1972; Adams \& Osborne, 1973; Benjamins et al., 1973; Poduslo \& Norton, 1973; T. V. Waehneldt \& V. Neuhoff, personal communication). In contrast, both light and heavy myelins are enriched in four major proteins of myelin, namely Wolfgram protein (Wolfgram, 1966), Folch-Lees proteolipid (Folch et al., 1957) and two basic proteins (which are characteristic of rat myelin) and a newly described myelin protein, DM-20 (Plate 2) from this laboratory (Agrawal et al., 1972). In addition, protein profiles of both light and heavy myelin were very similar to that of purified myelin prepared by the technique described previously from this laboratory (Agrawal et al., 1973).

Another approach to delineate a possible relation- 
ship between both myelin-like and membrane fractions and mature myelin is the use of radioactive isotopes to examine possible precursor-product relationships. Earlier experiments from Davison's laboratory (Agrawal et al., 1970b) were negative in this respect, probably because of the time-interval $(24 \mathrm{~h})$ involved and the choice of labelled compounds $\left(\left[1-{ }^{14} \mathrm{C}\right]\right.$ acetate and $\left[1-{ }^{14} \mathrm{C}\right]$ leucine), which have been shown to be metabolically active and capable of entering many biochemical pathways (Agrawal \& Prensky, 1973). The experiments reported in the present paper involved time-intervals after the injections of radioactive tracer as short as $15 \mathrm{~min}$ and extending for as long as $96 \mathrm{~h}$. Our choice of radioactive material was $\left[2,3-{ }^{3} \mathrm{H}\right]$ tryptophan for the following reason: Sammeck et al. (1971) has shown that this amino acid is not converted into other amino acids in the central nervous system nor will it form other metabolites of the tricarboxylic acid cycle (H. C. Agrawal, unpublished work). Therefore $\left[{ }^{3} \mathrm{H}\right]$ tryptophan can serve as a direct precursor of brain proteins. In addition, tryptophan will not label histone nor is it incorporated into brain lipids; thus the possibility of measuring radioactivity caused by histones and lipids that might be present with the myelin proteins is completely avoided.

Table 3 and Fig. 3 present clear evidence for the rapid incorporation of $\left[{ }^{3} \mathrm{H}\right]$ tryptophan into myelinlike membranes followed by a more gradual incorporation of radioactivity into myelin itself (Table 3). At $12 \mathrm{~h}$ after the injection of the radioisotope, the specific radioactivity of myelin-like subfraction and myelin appears to have equilibrated (Table 3).
However, incorporation continues and reaches a maximum $24 \mathrm{~h}$ later. This is in contrast with other brain subcellular fractions, where radioactivity is incorporated and then immediately begins to show a decline in relative specific radioactivity or remains at a rather constant value (Fig. 3). Thus the pattern of radioisotope incorporation and turnover is definitely different for myelin-like subfraction and myelin when compared with that of mitochondria, nerve-ending particles, and especially microsomal fractions (Fig. 3). The pattern observed for myelinlike subfraction and myelin is quite consistent with the required precursor-product relationship if myelin is derived from the myelin-like fraction. It is noteworthy that the relative-specific-radioactivity kinetics of myelin-like subfraction is very different from that of the microsomal fractions (Fig. 3). This would indicate that myelin-like material is not simply a microsomal preparation, but rather a discrete membrane fraction separable from microsomal fractions. The results of tracer studies argue against the suggestion of Norton (1971) that myelin-like material is simply a species of microsomal fraction.

Similar data have been obtained for the membrane fraction (described in the present paper) and light and heavy myelin fractions (Table 4; Fig. 2). Within $15 \mathrm{~min}$ after the injection of $\left[{ }^{3} \mathrm{H}\right]$ tryptophan, the membrane fraction is highly labelled, whereas both the light and heavy myelin have lower specific radioactivities. Again, all three fractions show increased specific radioactivity over a $24 \mathrm{~h}$ period, but the specific radioactivity of these fractions did not equilibrate until $24 \mathrm{~h}$. The relationship of the specific
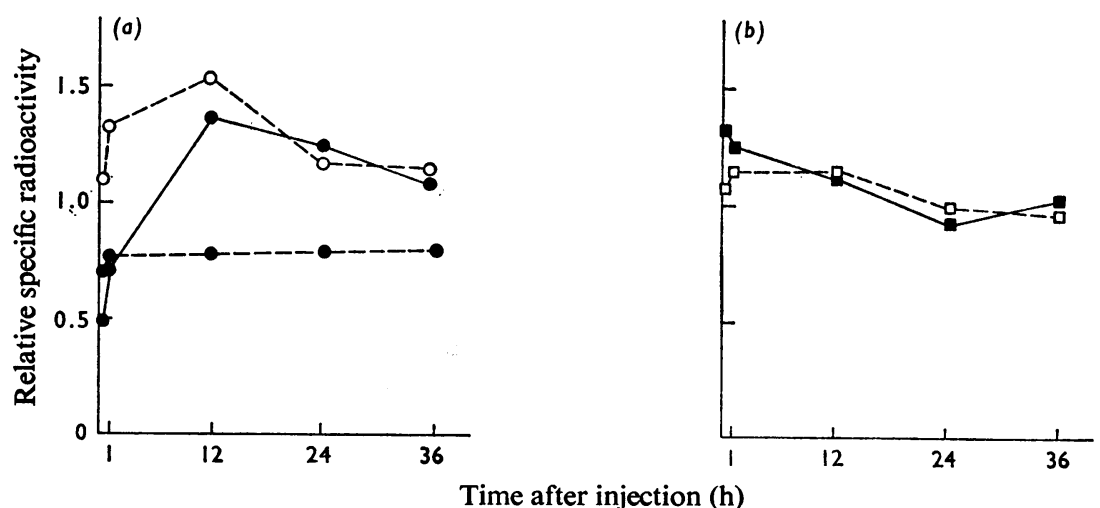

Time after injection (h)

Fig. 3. Relative specific radioactivity of myelin-like, myelin and other subcellular fractions of 15-day-old rat brain prepared by the technique of Agrawal et al. $(1970 b, 1973)$

The relative specific radioactivities of each fraction were determined by dividing the specific radioactivities (c.p.m./mg of protein) by the specific radioactivity of the homogenate to normalize the data. $(a)$ subfraction; ---- , nerve endings; $(b) \square$, microsomal fractions; $\square$, mitochondria. 
radioactivity of the membrane fraction to that of the two myelin fractions is suggestive of a precursorproduct relationship. It is noteworthy, and perplexing, that the specific radioactivity of the membrane fraction (precursor) 'equilibrated' with the myelin (product) even though non-radioactive myelin was being accumulated and the membrane fraction should have been depleted of radioactive material by deposition into the myelin sheath.

The fact that we were able to separate myelin into light and heavy myelin fractions from 15-day-old rat brain (as defined operationally by their flotation density) suggests that they represent different stages in formation of mature adult-type myelin. Thus, one would visualize a sequence of membrane fractions from myelin-like [or lower layer (Morell et al., 1972); D fraction (Benjamins et al., 1973); membrane fraction (present study)] through myelin subfractions to the adult mature myelin sheath. There is good evidence in the literature to support this concept, for Horrocks et al. (1966) and later other workers (Cuzner \& Davison, 1968; Eng \& Noble, 1968; Norton, 1971; Dalal \& Einstein, 1969; Norton \& Poduslo, 1973) demonstrated that the lipid composition of 'early myelin' from developing brain is strikingly different from mature myelin (see reviews by Norton, 1971; Agrawal \& Davison, 1973). Thus the lipid increases both qualitatively and quantitatively in the sequence of myelin-like and membrane fraction to heavy and light myelin. This is shown by the change in lipid composition and, in particular, by the marked accumulation of cerebrosides. It must be emphasized that the lipid data reported represent only single preparations of each myelin-like and membrane fraction and further more detailed analysis is needed. We were able to demonstrate a similar gradient from membrane fraction to heavy to light myelin in the activity of the $2^{\prime}: 3^{\prime}$-cyclic nucleotide 3'-phosphohydrolase and acetylcholinesterase (Table 2). Another possibility that must be considered is that the light and heavy myelin represent myelin membrane derived from different regions of the central nervous system or from different cell types (if myelin is not solely formed from one population of oligodendroglial cells). The ratios of the specific activities of the two enzymes $2^{\prime}: 3^{\prime}$-cyclic nucleotide $3^{\prime}$-phosphohydrolase and acetylcholinesterase show a progression from the membrane fraction to heavy to light myelin (the values being 216,977 and 8141 , respectively, Table 2). These results, coupled with our radioactive data showing a possible precursorproduct relationship between myelin-like or membrane fractions to myelin subfractions, are consistent with either hypothesis.

This work was supported in part by grants from the National Science Foundation (GB-36984), Allen P. and Josephine B. Green Foundation, Mexico, Mo., U.S.A., and U.S. Public Health Service Grants NS-05175-16 and 5-T01-NS-05051-19. We are indebted to Miss Lois Harper for preparing samples for electron microscopy, Dr. Blake W. Moore for preparing the synaptic plasmamembrane fractions, and Dr. D. C. DeVivo for measuring $\beta$-hydroxybutyrate dehydrogenase activity.

\section{References}

Adams, D. H. \& Osborne, J. (1973) Neurobiology 3, 91-122

Agrawal, H. C. \& Davison, A. N. (1973) in Biochemistry of Developing Brain (Himwich, W., ed.), vol. 1, pp. 143-186, Marcel Dekker Inc., New York

Agrawal, H. C. \& Prensky, A. L. (1973) Proc. Int. Meet. Int. Soc. Neurochem. 4th Tokyo, 550

Agrawal, H. C., Bone, A. H. \& Davison, A. N. (1970a) Biochem. J. 117, 325-331

Agrawal, H. C., Banik, N. L., Bone, A. H., Davison, A. N., Mitchell, R. F. \& Spohn, M. (1970b) Biochem. J. 120, 635-642

Agrawal, H. C., Burton, R. M., Fishman, M. A., Mitchell, R. F. \& Prensky, A. L. (1972) J. Neurochem. 19, 2083-2089

Agrawal, H. C., Trotter, J. L., Mitchell, R. F. \& Burton R. M. (1973) Biochem. J. 136, 1117-1119

Allison, J. H., Agrawal, H. C. \& Moore, B. W. (1974) Anal. Biochem. in the press

Banik, N. L. \& Davison, A. N. (1969) Biochem. J. 115, 1051-1062

Bartlett, G. R. (1959) J. Biol. Chem. 234, 466-471

Benjamins, J. A., Miller, K. \& McKhann, G. M. (1973) J. Neurochem. 20, 1563-1570

Braun, P. E. \& Barchi, R. L. (1972) Brain Res. 40, 437-444

Cotman, C. W. \& Matthews, D. A. (1971) Biochim. Biophys. Acta 249, 380-394

Courchaine, A. J., Miller, W. H. \& Stein, D. B., Jr. (1959) Clin. Chem. 5, 609-614

Cuzner, M. L. \& Davison, A. N. (1968) Biochem. J. 106, 29-34

Dalal, K. B. \& Einstein, E. R. (1969) Brain Res. 16, 441-451

Davison, A. N. \& Dobbing, J. (1966) Brit. Med. Bull. 22, 40-44

De Robertis, E., de Iraldi, A. P., Lores Arnaiz, R. D. \& Salganicoff, L. (1962) J. Neurochem. 9, 1-23

Ellman, G. L., Courtney, K. D., Andres, V., Jr. \& Featherstone, R. M. (1961) Biochem. Pharmacol. 7, 88-95

Eng, L. F. \& Noble, E. P. (1968) Lipids 3, 157-162

Folch, J., Lees, M. \& Sloane-Stanley, G. J. (1957) J. Biol. Chem. 226, 497-509

Hess, H. H. \& Lewin, E. (1965) J. Neurochem. 12, 205-211

Horrocks, L. A. (1968) J. Neurochem. 15, 483-488

Horrocks, L. A., Meckler, R. J. \& Collins, R. L. (1966) in Variations in Chemical Composition of the Nervous System (Ansell, G. B., ed.), p. 46, Pergamon Press Ltd., Oxford

Kurihara, T. \& Tsukada, Y. (1967) J. Neurochem. 14, 1167-1174

Lowry, O. H., Rosebrough, N. J., Farr, A. L. \& Randall, R. J. (1951) J. Biol. Chem. 193, 265-275

Morell, P., Greenfield, S., Costantino-Ceccarini, E. \& Wisniewski, H. (1972) J. Neurochem. 19, 2545-2554 
Norton, W. T. (1971) in Chemistry and Brain Development (Paoletti, R. \& Davison, A. N., ed.), Plenum Press, New York

Norton, W. T. \& Poduslo, S. E. (1973) J. Neurochem. 23, 759-773

Poduslo, S. E. \& Norton, W. T. (1973) Fed. Proc. Fed. Amer. Soc. Exp. Biol. 32, 485

Sammeck, R., Martenson, R. E. \& Brady, R. O. (1971) Brain Res. 34, 241-254
Siakotos, A. N., Kulkarni, S. \& Passo, S. (1971) Lipids 6, 254-259

Waehneldt, T. V. \& Mandel, P. (1972) Brain Res. 40, 419-436

Williamson, D. H., Bates, M. W., Page, M. A. \& Krebs, H. A. (1971) Biochem. J. 121, 41-47

Wolfgram, F. (1966) J. Neurochem. 13, 461-470

Zlatkis, A., Zak, B. \& Boyle, A. J. (1963) J. Lab. Clin. Med. 41, 486-492 